\title{
The Effects of Personality, Religiosity, and Sexual Orientation in Response to Sexual Appeals in Advertising
}

\author{
Erin Noble \\ Siena College \\ 515 Loudon Road, \\ Loudonville, NY 12211, USA \\ Michael Pepe \\ 515 Loudon Road, \\ Loudonville, NY 12211, USA
}

\begin{abstract}
Purpose- The purpose is to add valuable research to the marketing community about the effects of personality type and sexual orientation.

Design- The study is based upon the survey responses of a random group of people within the population in the United States. Five advertisements were selected for inclusion in the study was collected from Coors Light advertisements using sexual appeals with a combination of genders.

Findings- The results show that there is no direct relation between specific personality types and positive response to sexual appeals, mixed results among religiosity, and our hypotheses for straight men were proven right, while there were mixed results in our hypotheses for straight women.

Research Limitations/Implications- We had several limitations in our research based on the demographics of respondents.

Originality/Value- This research provides valuable insight into people's opinions on sex in advertising and whether it is an effective form of advertising.
\end{abstract}

Keywords: Personality Type, Sexual Orientation, Sex appeals, Sex in Advertising, Gender

\section{Introduction}

Advertising plays a crucial role in today's marketing. Companies are grabbing at the market trying to gain the most market share. One of the tactics companies have begun to use is sexual appeals in their advertisements. Sexual appeals are used to lure consumers in by appealing to their sexual desires and fantasies. By using sexual appeals, it really grabs the public eye and people's attention.

Sex Appeal is one of many advertising strategies that marketing professionals use to persuade people to buy a product, pay for a service, donate to a cause, or otherwise be persuaded. Sex appeal lures audiences by appealing to their sexual desires and fantasies. Advertisers use this approach because it is an easy and proven method for attracting attention quickly. Sex appeals can be very broad, the same person can respond both positively and negatively to sex appeal ads.

Sexual appeals do not just have to do with the attractiveness of a model. It is also not just the way the models are dressed or the type of contact between the two models. Sex appeals in advertising also include lighting, editing, sound, and verbal information, such as double entendre, suggestive language, or innuendo. According to research done by Tom Reichert, he found that consumers have, "four overarching characteristics of sexy ads: (1) physical features of models (clothing, physique, and general attractiveness), (2) behavior/movement, (3) intimacy between models, and (4) contextual features (e.g., camera effects)." In the study, both men and women most frequently mentioned the physical features category. However, women were more likely to mention contextual features and intimacy category than men.

All sexual appeals can be used in any form of advertisement or commercial through various channels. In Jacqueline Lambiase Tom Reichert's 2004 article, Sex in Advertising, he states that "Up to 10\% of television commercials contain sexual content, compared to a higher proportion in magazine and Internet ads." Advertising containing sexual appeals can be seen anywhere by anyone because they are on so many different channels.

Sex appeal advertising is a legitimate tactic used by many companies. The goal for these companies is to stand out in the media. According to Clow and Baack (2007), sex appeal is a legitimate tactic, "if used in a manner that is interesting, germane to the products and within the ethical standing of the region". Increasingly, sex appeals in advertising have been used to suggest that it is an effective marketing tool. 
However, this marketing tactic is very controversial and very highly debated. Many people perceive this tactic as unethical and inappropriate. These same people generally doubt the effectiveness of this tactic.

Whether or not sexual appeals in advertising are effective are based on key demographics. One of these key demographics is an individual's' personality type. Another key demographic is an individual's' sexual orientation. The last main key demographic is an individual's' religiosity. There are three main key demographics, however, gender, income, education, and several other demographics can also play a role in consumer's response to sexual appeals used in advertising. Each demographic in the study will be tested based on the appropriate scales for each of them.

In order to test an individual's personality type, we plan to utilize the NEO Five-Factor Inventory scale. This scale was developed to provide a concise measure of the five basic personality types: neuroticism, extraversion, openness, agreeableness, and conscientiousness. The NEO Five-Factor Inventory contains 60 items and is measured using a fivepoint Likert scale. We will also be using a five-point Likert scale to test for religiosity. We will be using nominal scales to measure sexual orientation as well as the other various other demographic questions.

In addition to the consumer's key demographics, another factor that plays a role is what is happening in the advertisement. Some consumers may be inclined to purchase a product based on the gender of the model or models within the advertisement. If the advertisement suggests sexual promiscuity between two people of the same gender this may lead to a consumer being less or more likely to buy the product based on the consumer's personality type and sexual orientation along with other key demographics.

This study will explore how the gender of the model(s) along with the consumers' demographics will play a role in the response to sexual appeals used in advertising. We will use five advertisements with a combination of a single model and two models with a mix of genders in each advertisement to see how a consumer responds to these advertisements for the same product.

\section{Literature Review}

According to Reichert, sexual appeals are defined as brand messages that contain visual and/or textual information with the purpose of selling branded goods. Some of these appeals include sexual suggestiveness and full or partial nudity. Sexual appeals are a commonly used technique to promote products. The tactic originally started in western societies; however, it is even spreading to places like China. Even though sexual appeals are a widely used tactic when it comes to advertising there are mixed views on whether it is an effective form of advertising.

Lambiase and Reichert, "conceptualize five types of sexual information in advertising, namely, nudity, sexual behavior, physical attractiveness, sexual referents and sexual embeds". The case for nudity is very apparent. If an individual is nude it is easy to see the individual in a sexual way. In the case of sexual behaviors, models in advertisements can act flirty, smile, position or move themselves in sexual ways. All of these have the same goal of drawing the viewer in by using themselves in a sexual way. Similarly, the viewers will only process the advertisement as sexual information if they are attracted to the model. Sexual referents refer to the words and phrases advertisers use in order to draw a viewer in. These referents a lot of times include sexual innuendos. Sexual embeds are defined as "referents or forms of sexual representation designed to be perceived subconsciously" (Anabila, P., Tagoe, C., and Asare, S., 2016). Common types of embeds include objects that are shaped or positioned like genitalia. Sexual embeds can also be small hidden messages of naked people and body parts.

Earlier research suggests that both males and females will react negatively to ads that use sex appeal because they are perceived as unethical and manipulative. Now, being in the $20^{\text {th }}$ century we know this is not true.A recent study found that "under the sort of constrained processing conditions that allow the elicitation of spontaneous, gut-level reactions, men on average will exhibit a more positive attitudinal response to gratuitous sex appeals than women" (Sengupta and Dahl, 2008). This study shows that people's opinion on sex in advertising is changing.

The results from experimental findings show that people are attracted to a sexy and seductive opposite sex (Peterson, R.A. and Kerin, R.A., 1977, 59-63). These results can be confirmed by numerous different studies. One study by Mager and Helgeson's in 2011 reported an increasing trend of models positioned in suggestive ways in advertising. These studies all drew one common conclusion and that was that outright nudity is not preferred in advertisements.

Sexual appeals in advertising is a legitimate tactic used by many companies who have a goal of making a big splash into the media landscape. According to Clow and Baack, "sex appeal is a legitimate tactic if used in a manner that is interesting, germane to the products and within the ethical standards of the region." Even though more and more companies are beginning to utilize this tactic there is no ignoring that it is controversial. Companies believe this is a useful technique because it is a useful 'attention-getter' meaning that it grabs people's attention very quickly. It is also assumed to be effective because it leads to a large increase in sales. 
According to Peter Anabila, Clement Tagoe, and Sylvester Asare, "another phenomenon probably reinforcing the use of sex appeals in advertising on a wider scale is the trend towards homogenization of cultures due to globalization, thus making cultures more open to things prevailing in other cultures". A lot of products across different global areas all utilize sexual appeals and no matter what company is selling them they almost always utilize sexual appeals. These products include music videos, alcoholic beverages, condoms, cosmetics, soaps, and various others. Product categories with dominant sex appeal ad

Most of the literature suggests that advertisements with sexual appeals outperform advertisements that do not use sexual appeal tactics, there are some contradictory findings. According to James King, "Parker and Furnham (2007) failed to find an effect of sexual content on recall, and Fried and Johnson (2008) provided evidence to suggest that sexual content can be a distraction that interferes with the processing of the product information" (King, J., McClelland, A., and Furnham, A., 2015, 1).

Howard Lavine, Donna Sweeney, and Stephen H. Wagner conducted a study to examine consumer's response to seeing an advertisement depicting a model in a sexual way. The study found: "that women exposed to sexist ads judged their current body size as larger and revealed a larger discrepancy between their actual and ideal body sizes (preferring a thinner body) than women exposed to the nonsexist or no ad condition. Men exposed to the sexist ads judged their current body size as thinner, revealed a larger discrepancy between their actual and ideal body size (preferring a larger body), and revealed a larger discrepancy between their own ideal body size and their perceptions of others' male body size preferences (believing that others preferred a larger ideal) than men exposed to the nonsexist or no ad condition". We can see that both men and women may have an initial negative feeling towards themselves when seeing an advertisement using an attractive model to sell a product or service. Depending on the product consumers may purchase the product just to try to associate themselves with the model in the advertisement.

A similar study conducted by Darren W. Dahl, Jaideep Sengupta, Kathleen D. Vohs showed differing results from the one conducted by Lavine, Sweeney, and Wagner. This study draws on the differences between men and women's attitudes about sex in advertising. They found that "either as an end in itself (men) or as inextricably linked to relationship commitment (woman) to understand attitudes toward the gratuitous use of sex in advertising". The results of the four experiments showed that women's spontaneous dislike of sexual ads softened when the ad could be interpreted in terms of commitment-related resources. In contrast, men's positive attitudes toward sexual ads were relatively unaffected by the salience of relationship commitment cues. The study brings in the interesting point that sex appeal tactics may not be enough to convince a consumer to buy a product instead the intent of the message needs to be something consumers can align themselves with.

Individuals responded differently to the use of sexual appeals in advertisements based on their personality type. Based on results of a study conducted by Iain R. Black, George C. Organ, and Peta Morton, the results show that individuals who scored higher in extraversion based on the NEO-Five Factor Inventory responded more favorably to advertisements using sexual appeals. The study found that there was no connection between neuroticism and openness and the favorability of advertisements using sexual appeals. The study did not observe whether conscientiousness or agreeableness as a personality type played into whether an individual has favorability towards advertisements using sexual appeals. The study further investigated whether gender played a role in an individual has favorability towards advertisements using sexual appeals and found that gender was not a factor.

Through research, an individual's religiosity plays an effect on how they will respond to sexual appeals used in advertising. According to Dr. Michael Pepe, "religiosity is traditionally under the cultural and psychological fields of study, its relevance to consumer behavior has been well documented" (Pepe, 2). A consumer's behavior is dictated in some sense towards their religiosity. The more religious an individual is the more likely they are to be offended by certain aspects of advertising. Sexual appeals in advertising can be extremely offensive to some individuals who are more religious.

Another factor that plays into an individual's preference for sexual appeal in advertising is sexual orientation. A study found that "for overt manipulations of both gay male and lesbian images in ads, the homosexual population shows a strong positive response" (Dotson, M.J., Hyatt, E.M., and Thompson, L.P., 2009, 431-447). The researchers used a Ttest to calculate the results. The study used five different brands which included, Diesel, Levi's, Versace, Prada, and Ralph Lauren. The mean score for each brand varied greatly. The greatest difference between homosexual and heterosexual preference can be seen in the Diesel brand. For Diesel, the mean score for homosexuals was 5.64, while for heterosexuals the mean score was 2.71. The scores were closer for the brand Prada with a mean score for homosexuals of 4.56 and heterosexuals of 4.14. This study shows that homosexuals are more likely to prefer brands that are using models who are portrayed as homosexuals than people who are heterosexual will. 
The study also shows that homosexuals and heterosexuals can share similar views on the use of models who are homosexuals or portrayed as homosexuals depending on the brand of the advertisement.

\section{Theoretical Framework}

Based on our research we generated our own theoretical framework. We recognized that the framework needed to be holistic of all the variables we were studying. Our theoretical framework can be broken down into the following categories; personality traits, sexual orientation, religiosity, gender, and various other demographic variables. All these variables lead us to an understanding of an individual's feelings towards an advertisement.

The first variable is personality traits. In order to be able to further analyze an individual's personality, we are using the NEO Five-Factor Inventory scale ${ }^{1}$ to determine whether an individual classifies more as extraversion, neuroticism, or openness. From here we will be able to determine an individual's feelings towards an advertisement based on their personality.

For the other demographic variables, we are using a series of questions to get specific demographic information on the individual. For example, when it comes to religiosity, we will be using a five-point Likert scale to determine how an individual evaluates the strength of their religious affiliation. For the other demographic variables, such as sexual orientation, age, and income we will be using a series of multiple choice and open-ended questions to determine if there is a correlation with these demographic variables and an individual's feelings towards an advertisement. ${ }^{2}$

\section{Hypotheses}

Each of our hypotheses is broken down into three different areas based on our research and on our own beliefs. Within each of these categories, we have hypotheses that we believe will be proven in the results of our study.

Based on the individual's personality type we believe if the individual is considered more extraverted, they will respond more in favor of sexual appeals used in advertising. However, if an individual is more conscientious, they will respond very unfavorable to sexual appeals used in advertising.

$H_{1}$ : There is a significant positive relationship between participant's scores on the extraversion scale and a more favorable response to sexual appeals in advertising.

$\mathrm{H}_{2}$ : There is a significant negative relationship between participant's scores on the neuroticism scale and a more favorable response to sexual appeals in advertising.

$H_{3}$ : There is a significant positive relationship between participant's scores on the openness scale and a more favorable response to sexual appeals in advertising.

Based on the individual's religiosity WILL depend on whether they like or dislike sexual appeals in advertising. We hypothesize that the more religious an individual is the less likely they are to respond to sexual appeals in advertising in a positive way.

$H_{4}$ : The more religious an individual is the less likely they are to respond positively to sexual appeals in advertising (and vice-versa)

There have drawn several hypotheses based on the individual's sexual orientation. It has been hypothesized that straight men and straight female will respond positively to seeing their opposite-sex portrayed in an advertisement using sexual appeals. While it has also been hypothesized that straight men and straight women will not respond positively to seeing their same sex portrayed in an advertisement using sexual appeals. It has been hypothesized that gay men or lesbian women will respond positively to seeing their same sex portrayed in an advertisement using sexual appeals. Lastly, it has been hypothesized that gay men and lesbian women will not respond positively to seeing their same sex portrayed in an advertisement using sexual appeals.

$H_{5}$ : Straight men are likely to respond positively to seeing their opposite-sex in an advertisement using sexual appeals.

$H_{6}$ : Straight women are likely to respond positively to seeing their opposite-sex in an advertisement using sexual appeals.

$H_{7}$ : Straight men are likely to respond negatively to seeing their same sex in an advertisement using sexual appeals.

$H_{8}$ : Straight women are likely to respond negatively to seeing their same sex in an advertisement using sexual appeals.

The last demographic areas included in this study are age, income, number of children, and marital status. Each one of these key variables can play a role in whether an individual will respond favorably to sexual appeals in advertising.

\footnotetext{
${ }^{1}$ See Table 1 in Appendix "Revised NEO FFI Scale"

${ }^{2}$ See Figure 3 in Appendix "Attitudes Towards an Advertisement"
} 
Some parents respond negatively to their sexual appeals in advertising because they do not want their children exposed to them. Some generations do not respond favorably to advertisements that use sexual appeals. Typically, older generations respond less favorably than younger generations. Each of these hypotheses will evaluate these demographic variables to see if there is any significant relationship between these variables and response to sexual appeals.

$H_{10}$ : There is a significant negative relationship between age and favorable response to advertisements featuring same sex couples.

$H_{11}$ : There is a significant relationship between income and favorable responses to sexual appeals advertisements.

$H_{12}$ : There is a significant relationship between the number of children of participants and favorable responses to sexual appeals advertisements.

\section{Method}

This experiment was conducted throughout the United States. The survey was created through Qualtrics. In total there were fourteen questions on the survey. The questions varied in length. Responses to each question will be used to draw conclusions between response to sexual appeals in advertising and specific demographics of the individual. The time for completion of the survey was between ten and fifteen minutes. The survey was distributed through several different channels to participants. In the survey there were five different Coors Lights advertisements featured. Each of these five advertisements are tools used in assisting consumers response to sexual appeals based on key demographic variables. After the completion of the study, the data was analyzed using a combination of Excel and SPSS.

\subsection{Measurement Instruments}

A multitude of scales will be used in order to assess each variable of an individual's demographic characteristics. In order to properly assess an individual's personality type, the results will be analyzed using the scale of the five-factor inventory. The scale for religiosity will be based on a five-point Likert scale. Other demographic questions will be assessed based on multiple choice answers, short-answers, and semantic scales.

\subsection{Sample}

A total of 287 individuals participated in the survey, however, there were only 199 valid responses. The sample was mostly consistent with college-aged students. There was an age restriction on the survey in order to avoid any consent and legality issues. The survey sample also consisted of adults from a wide age range with the oldest participant being 78 years old. Most of the participants were also female. The distribution was 110 female, 85 male, one transgender, and two participants did not respond. Most of our respondents also identified as straight. The breakdown is 183 respondents identified as straight, two as gay, eight as bisexual, one as queer, one as other, and then four participants either did not want to disclose that information or chose not to respond. Most of the respondents also identified as Caucasian, white.

\subsection{Procedure/Distribution}

As stated previously, the survey was distributed through a reusable link. The link to the survey was sent out through email. The link was also distributed through social media pages and through asking professors, friends, family, peers, employers, and various other individuals to complete the survey an encourage people they know to complete the survey.

The survey ran for approximately three weeks. After the three weeks, the data began to be analyzed. Specific scoring guidelines were used when it came to measure each individual participant's personality type. As previously stated, the data were analyzed through a mixture of Excel and SPSS. With the use of data analytic techniques, several correlations were drawn between the data.

\section{Results}

Based on the data from our study we have been able to gather numerous results based on several demographic variables. This study was specifically looking at three key variables sexual, which were personality, religiosity, and sexual orientation. Based on these three key demographic variables there were several hypotheses made. With the data analyzed correlations can be seen with my hypotheses and the data.

\subsection{Personality}

There were three hypotheses made based on participant's personality type. Each one of these hypotheses was based on previous research done. My hypothesis was contradictory of previous research. Each one of my three hypotheses were not supported based on the data we collected throughout this study. 
$\mathrm{H}_{1}$ hypothesized there is a significant positive relationship between participant's scores on the extraversion scale and a more favorable response to sexual appeals in advertising. The results indicate there is no significant relationship between an individual's' extraversion score and their response to sexual appeals for all five advertisements presented as the $\mathrm{p}$ values all exceeded .05. Therefore, the hypothesis is not supported.

$\mathrm{H}_{2}$ hypothesized there is a significant negative relationship between participant's scores on the neuroticism scale and a more favorable response to sexual appeals in advertising. The results indicate there is no significant relationship between an individual's' openness score and their response to sexual appeals for four advertisements presented as the $p$ values all exceeded .05. Therefore, the hypothesis is not supported. Ad \#3, featuring a male and female resulted in a significant negative relationship with a p-value of .017.

$\mathrm{H}_{3}$ hypothesized there is a significant positive relationship between participant's scores on the openness scale and a more favorable response to sexual appeals in advertising. The results indicate there is a significant relationship between an individual's' openness score and their response to sexual appeals for the two advertisements featuring individuals of the same gender. The $\mathrm{p}$ values were .048 and .050 . The three advertisements that featured a female only, a male only and both a male and female had $\mathrm{p}$ values exceeding .05. Therefore, the hypothesis is not supported for those three advertisements.

\subsection{Religiosity}

For the key variable demographic religiosity, there was one hypothesis made. $\mathrm{H}_{4}$ hypothesized the more religious an individual is the less likely they are to respond positively to sexual appeals in advertising (and vice-versa). The results indicated that only the ad featuring a male only had a significant positive relationship with the level of religious beliefs and a favorable response to the advertisement. There were no significant relationships found between the level of religiosity and the other four advertisements.

\subsection{Sexual Orientation}

For the key demographic variable, sexual orientation, there were four hypotheses predicted based on the limited research available in for this variable. $\mathrm{H}_{5}$ hypothesized that straight men are likely to respond positively to seeing their opposite-sex in an advertisement using sexual appeals. A paired samples t-test was generated and resulted in finding there was a significant difference in the favorable level of response from straight men toward the advertisement only depicting the female alone versus the other four ads. The p-value was less than .05 in all instances providing support for the hypothesis.

$\mathrm{H}_{6}$ hypothesized that straight women are likely to respond positively to seeing their opposite-sex in an advertisement using sexual appeals. A paired samples t-test rejected the hypothesis with a p-value of .089 as there was not a significant difference between responses to the advertisement featuring a female only compared to a male only. Females had a more favorable response to the female only ad compared to the ad with the male only.

$\mathrm{H}_{7}$ hypothesized that straight men are likely to respond negatively to seeing their same sex in an advertisement using sexual appeals. A paired samples t-test was generated and resulted in findings that there was a significant difference between the responses from straight men toward the advertisement depicting two males versus the other four ads. The p-value was greater than .05 in all instances providing support for the hypothesis.

$\mathrm{H}_{8}$ hypothesized that straight women are likely to respond negatively to seeing their same sex in an advertisement using sexual appeals. A paired samples t-test rejected the hypothesis. The opposite occurred as there was a significantly higher favorable response from women towards the advertisements featuring both females and both males compared to the other three ads.

\subsection{Other Key Demographic Variables}

$\mathrm{H}_{10}$ hypothesized there is a significant negative relationship between age and favorable response to advertisements featuring same sex couples. Correlation tests results found a significant positive relationship with a $\mathrm{p}$ value .018 between age and a higher favorable response to the advertisement featuring two females. Therefore, the hypothesis is not supported.

$\mathrm{H}_{11}$ hypothesized there is a significant relationship between income and favorable responses to sexual appeals advertisements. Correlation tests results found a significant positive relationship with a $p$ value .007 between income levels and a higher favorable response to the advertisement featuring a female and male.

$\mathrm{H}_{12}$ hypothesized there is a significant relationship between the number of children of participants and favorable responses to sexual appeals advertisements. Correlation tests results found a significant positive relationship with a $p$ value .021 between the number of children of participants and a higher favorable response to the advertisement featuring two females. 


\section{Theoretical Contributions}

An individual's personality traits as measured by their level of neuroticism, extraversion and openness had no significant relationship with their response to the various ads. The results contrast with the general theory that personality does have a significant influence on how people respond to sexual appeals in advertising. Therefore, this research identifies the need to further analyze the impact of personality traits on how individuals respond to sexual appeals in advertising.

Individuals scoring high on the openness scale are many times described as imaginative, curious and willing to entertain novel ideas and unconventional values. The results in this study support this notion as open-minded people had a significantly favorable response to the advertisements depicting two males and two females.

The findings of the study indicate that males do not respond favorably to advertisements featuring same-sex couples. Marketers need to proceed with caution when considering running advertisements of LGBT on platforms viewed mainly by males. Females are more open-minded and accepting of advertisements featuring same-sex couples. It is recommended that marketers run ads of same-sex couples that target a female audience.

The findings show that there is a significant relationship between income and favorable response to sexual appeals in advertising. The lower an individual's income in the more favorably they respond to advertisements with sexual appeals. This indicates that researchers should focus on putting advertisements that utilize sexual appeals on platforms that are meant for people with moderate to low income. These types of advertisements should not be featured on platforms that are targeted towards individuals with a high level of income.

The study showed that there is a significant relationship between number of children and favorable response to sexual appeals in advertisements. The results showed that the more children an individual has the less favorable they are to advertisements that feature sexual appeals. One reason for this could be that they do not want their children exposed to advertisements that have sexual appeals. Either way, it is important that advertisers do not put advertisements with sexual appeals on family platforms. Advertiser's should utilize platforms that are targeted towards adults without children.

Due to the data found in the study conducted advertisers have gained insight into how to target specific groups of people based on key demographic variables. Based on the data advertisers should target individuals with lower income when using sexual appeals. Generally, advertisers should not advertise towards individuals with children because they have a negative relationship with sexual appeals. Advertisers should try to have advertisements that utilize sexual appeals in magazines, T.V. programs, and other forms in which single, low-income individuals with no children are the main demographic because based on our results that is where these advertisements will be the most successful.

\section{Limitations and Future Research}

The main limitation of this research is that most of this sample was college-aged students. While, it is great to get the opinion of the up-and-coming generation, in order to have a more well-rounded idea of individuals' response to sexual appeals in advertising it would have been beneficial to have a more evenly distributed age of respondents. Another limitation was that there was also not a wide variety of respondents with different sexual orientations. It would have been more beneficial to have a wide variety of respondents with different sexual orientations. Most of the respondents were of the same race and it would have been more beneficial if the respondents were from a broader variety of races. A final limitation was that the survey did not ask respondents their attitude towards the brand, Miller Light, before the survey. Respondents could have bias views on Coors Light that could have disrupted the survey results.

\section{References}

Anabila, P., Tagoe, C., and Asare, S. (January 7, 2016). Consumer Perception of Sex Appeal Advertising: A High Context Cultural Perspective. The IUP Journal of Marketing Management. Vol. XIV, No. 4, pp. 34-55. Retrieved from https://ssrn.com/abstract=2712187

Black, I. R., Organ, G. C., and Morton, P. (2010). The effect of personality on response to sexual appeals. European Journal of Marketing. Vol. 44 Issue: 9/10, pp.1453-1477. Retrieved from https://doi.org/10.1108/030905610110629

Clow, K. E. and Baack, D. (2007). Integrated Advertising, Promotion, and Marketing

Communications. 3rd Edition, Pearson, Prentice Hall, Woodland Hills, CA.

Dahl, D.W., Sengupta, J., and Vohs K. D. Sex in Advertising: Gender Differences and the Role of Relationship Commitment. Journal of Consumer Research. Volume 36, Issue 2, 1. Pages 215-231. Retrieved from https://doi.org/10.1086/597158. 
Dotson, M. J., Hyatt, E. M., and Thompson, L. P. (2009). Sexual orientation and gender effects of exposure to gayand lesbian- themed fashion advertisements". Journal of Fashion Marketing and Management: An International Journal. Vol. 13 Issue: 3, pp.431-447, Retrieved from https://doi.org/10.1108/13612020910974537

King, J., McClelland, A., and Furnham, A. (2015). Sex Really Does Sell: The Recall of Sexual and Non- sexual Television Advertisements in Sexual and Non- sexual Programmes.

Lambiase, J. and Reichert ,T. (2003). Sex in Advertising. Lawrence Erlbaum Associates.

Lavine, H., Sweeney, D., and Wagner, S.H. (1 August 1999). Depicting Women as Sex Objects in Television Advertising: Effects on Body Dissatisfaction. Personality and Social Psychology Bulletin. Vol 25, Issue 8, pp. 1049 - 1058. Retrieved from http://journals.sagepub.com/doi/abs/10.1177/01461672992511012\#articleCitationDownloadContainer.

Mager, J., \& Helgeson, J. G. (2011). Fifty years of advertising images: Some changing perspectives on role portrayals along with enduringconsistencies. Sex Roles: A Journal of Research, 64(3-4), 238-252.

Pepe, M. (2015). A Preliminary Examination of Cultural Values as Antecedents of AttitudeToward the Ad In Turkish Consumers.

Peterson, R.A. and Kerin, R.A., (1977), “The female role in advertisements: Some experimentalevidence," Journal of Marketing, 59-63

Reichert, T. and Ramirez, A. (2000). Defining Sexually Oriented Appeals in Advertising: a Grounded Theory Investigation. NA - Advances in Consumer Research Volume 27, eds. Stephen J. Hoch and Robert J. Meyer, Provo, UT: Association for Consumer Research, Pages: 267-273.

Reichert, T. and Carpenter, C. (December 2004). An Update on Sex in Magazine Advertising: 1983-2003. Journalism and Mass Communication Quarterly. Retrieved from http://journals.sagepub.com/doi/abs/10.1177/107769900408100407.

Sengupta, J. and Dahl, D. W. Gender-Related Reactions to Gratuitous Sex Appeals in Advertising. Journal of Consumer Psychology. Volume 18, Issue 1, January 2008, pp. 62-78.

Table and Figures

\section{Figure 1- Sozodont Girl}

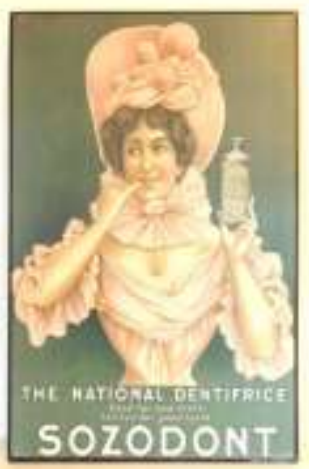

Figure 2 - White Rock Girl

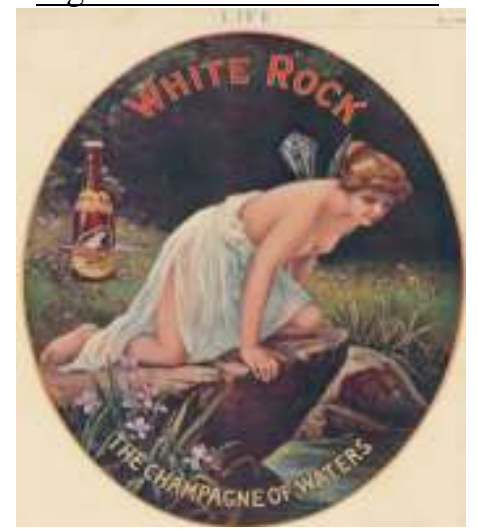




\section{Figure 3 - Scales for Attitudes Towards the Advertisements}

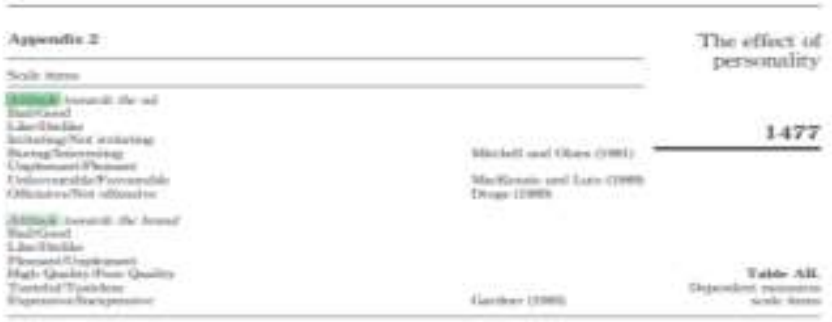

MacKenzie, S.B. and Lutz, R.J. (1989), "An empirical examination of the structural antecedents of attitude toward the ad in an advertising pretesting context", Journal of Marketing, Vol. 53 No. 2, pp. 48-65.

Mitchell, A.A. and Olsen, J.C. (1981), "Are product attribute beliefs the only mediator of advertising effects on brand attitude?", Journal of Marketing Research, Vol. 18, August, pp. 318-32.

Droge, C. (1989), "Shaping the route to attitude change: central versus peripheral processing through comparative versus noncomparative advertising", Journal of Marketing Research, Vol. 26, May, pp. 193-204.

Figure 4 - Theoretical Framework

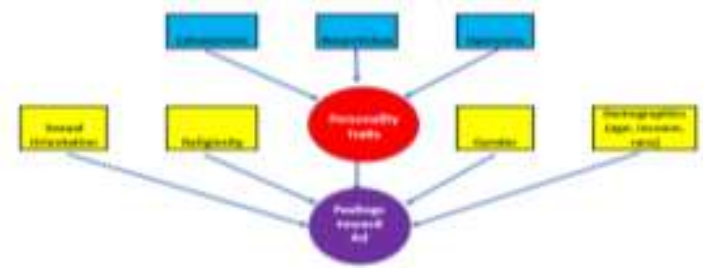

$\underline{\text { Advertisements }}$

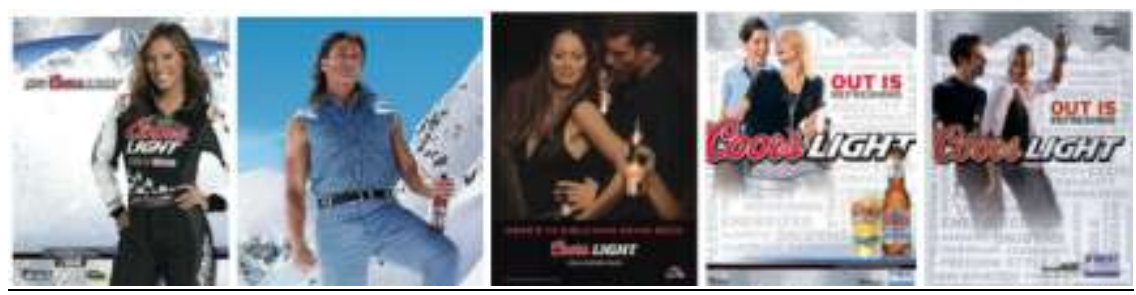

Table 1 - Revised NEO FFI Scale

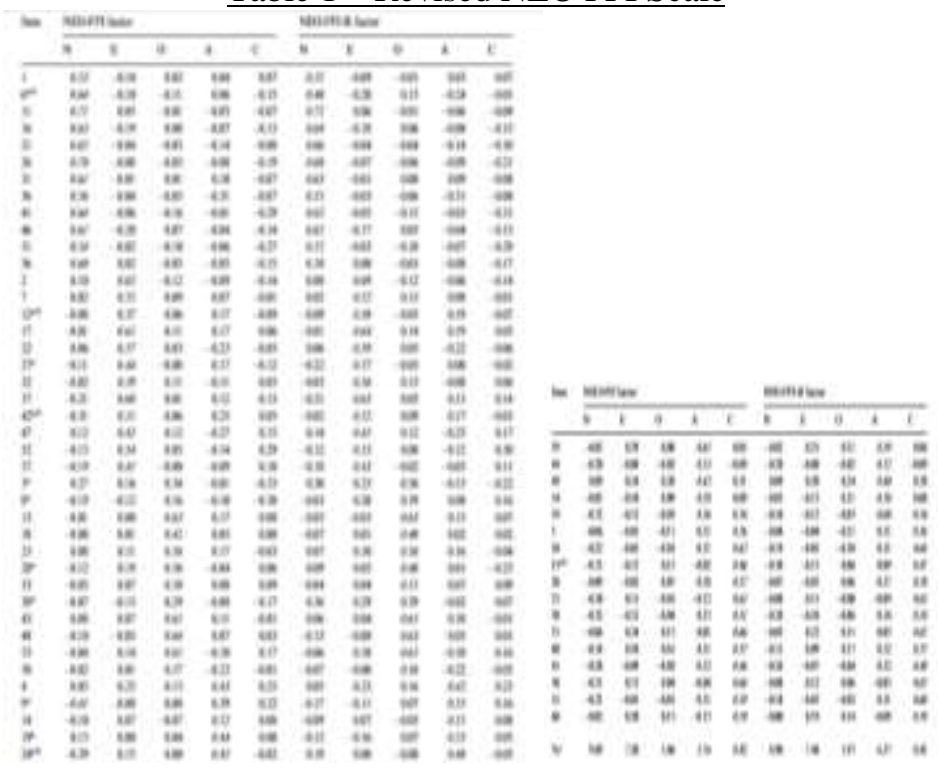


Table 2 - Sample Population

\begin{tabular}{|c|c|c|c|c|c|c|}
\hline \multicolumn{7}{|c|}{ Stuntion } \\
\hline & & 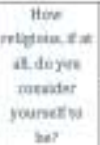 &  & 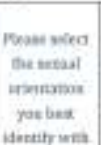 &  & $\begin{array}{c}\text { What is yout } \\
\text { ang? }\end{array}$ \\
\hline \multirow[t]{2}{*}{ K } & Vatal & 197 & 197 & 196 & 397 & 195 \\
\hline & Biletise & 3 & a & ] & 2. & 4 \\
\hline \multicolumn{2}{|c|}{ Hias } & 195 & 1.59 & 124 & 305 & 29.66 \\
\hline \multicolumn{2}{|c|}{ Mtain } & 260 & 290 & 109 & 300 & Hise \\
\hline \multicolumn{2}{|c|}{ Host } & + & 2] & 1 & 3 & 11 \\
\hline
\end{tabular}

\begin{tabular}{|c|c|c|c|c|c|}
\hline \multicolumn{6}{|c|}{ Satitios } \\
\hline & & 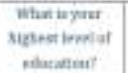 & $\begin{array}{l}\text { What is yen } \\
\text { anmal teramer }\end{array}$ & 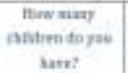 & $\begin{array}{l}\text { What iant } \\
\text { donfltes your } \\
\text { martial natian }\end{array}$ \\
\hline \multirow[t]{2}{*}{$\pi$} & Waiti & 197 & 40 & 163 & 134 \\
\hline & Haxage & 2 & 150 & 36 & t \\
\hline \multicolumn{2}{|c|}{ Mras } & 2.15 & 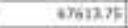 & 57 & ist \\
\hline \multicolumn{2}{|c|}{ Meast } & 290 & 3TSAse & $a v$ & 190 \\
\hline \multicolumn{2}{|c|}{ Mast } & , & D & D & 3 \\
\hline
\end{tabular}

Table 3 -Correlations for Personality
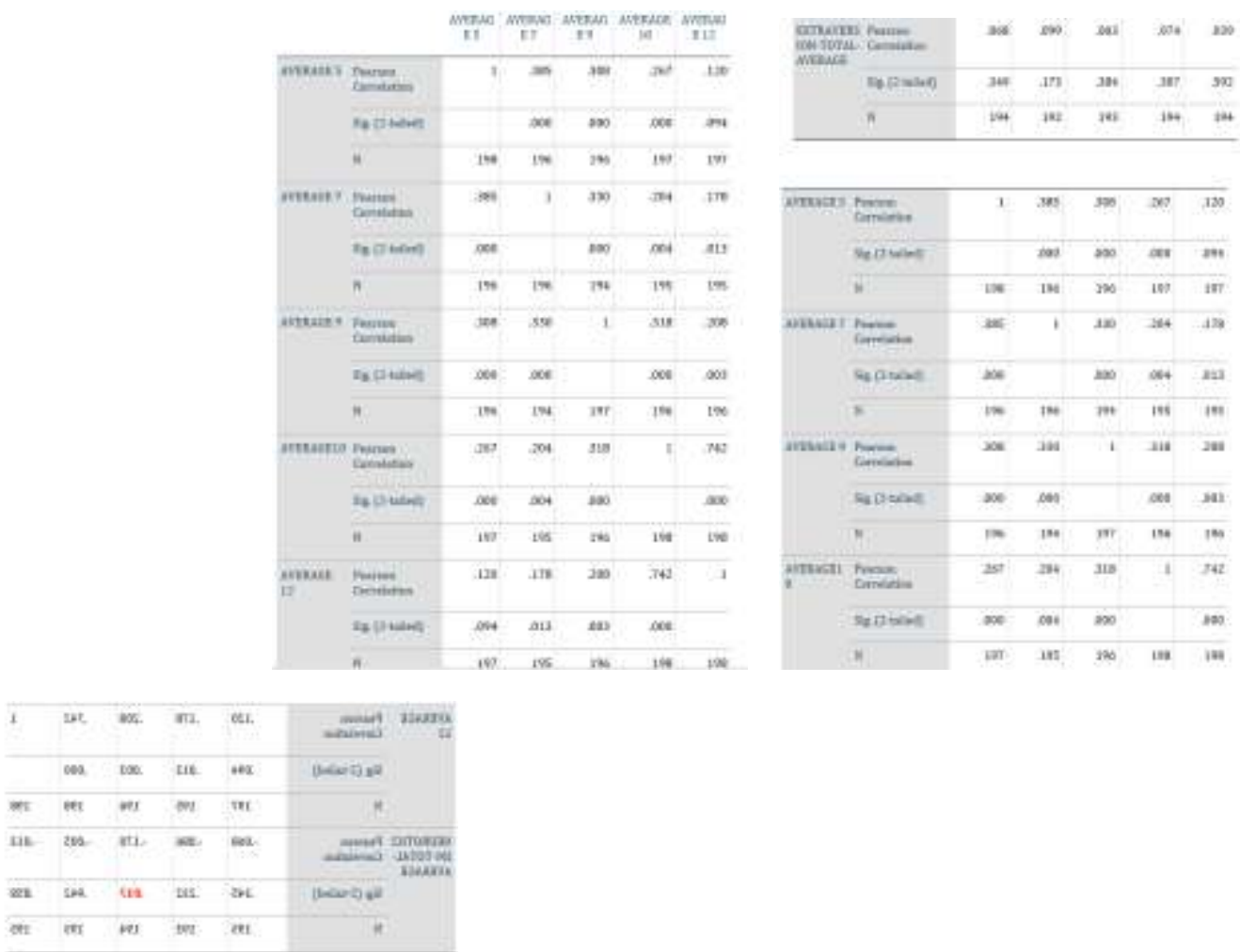

\begin{tabular}{|c|c|c|c|c|c|c|c|c|c|c|c|c|c|}
\hline III & ${ }_{\text {ansin }}^{\text {ansing }}$ & sousin & in & mons & & & \multirow{2}{*}{ AVEKACEIS } & Permintion & 267 & $20 t$ & 318 & 1 & 742 \\
\hline$=4$ & $\mathrm{cat}$ & we. & $2 a$ & I & $\ldots$ & rasure & & Tie $[2$-ealiean) & noo & - 004 & 000 & & .000 \\
\hline ne & $\mathrm{sen}$ & 600 & wa. & & คดvatex & & & $\pi$ & 107 & 105 & 198 & 190 & 196 \\
\hline wi & $\sin$ & ate & $m i$ & wa & in & & Avтsacr 12 & $\begin{array}{l}\text { Parran } \\
\text { Cimputian }\end{array}$ & .220 & $17 n$ & .200 & 742 & 1 \\
\hline mi & at: & ent & $\mathrm{r}$ & $m$ : & $\min$ & thestik & & & & & & & \\
\hline & & & & & neme? & & & Sie $[2$ taine $]$ & D04 & .013 & 0003 & 000 & \\
\hline na & $m$ & $\cos$ & & $\infty$ & monat. & & & $\mathrm{s}$ & 197 & 195 & 196 & tos & 198 \\
\hline si & $z i t$ & Hit & wii & $\$ 4$ & $y$ & & OrEYNIIS & Nowata & 044 & oos & -087 & $14 x$ & .177 \\
\hline$n$ & en & I & 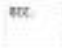 & $=x$ & singer & cteomis & $\begin{array}{l}\text { FOTAX } \\
\text { AVESACE }\end{array}$ & Perrestitan & & & & & \\
\hline 100 & $m$ & & $m$ & met & sevtiot & & & the (2-ailient) & S45 & 491 & 427 & .048 & .056 \\
\hline nat. & แA & $5 n$ & at & wat & " & & & N & 195 & 193 & 194 & 195 & 195 \\
\hline
\end{tabular}


$\underline{\text { Table } 4 \text {-Correlations for Sexual Orientation }}$

\begin{tabular}{|c|c|c|c|c|c|}
\hline & & Expancy & Evromt & $\begin{array}{l}\text { natar } \\
\text { Amont }\end{array}$ & $\begin{array}{l}\text { Crmalutsx } \\
\text { Emmat }\end{array}$ \\
\hline \multirow[t]{7}{*}{ wis } & Imouns & נ193 & 200 & 234 & $u_{1}$ \\
\hline & the & 2 & 10 & H. & w \\
\hline & Darned & 3 & ts & 21 & 3ss \\
\hline & bee & t & $s$ & $s$ & 28. \\
\hline & Fater & 2 & 5 & 5 & 3us \\
\hline & 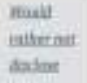 & $t$ & $s$ & s & ross \\
\hline & nias & I2s & Nes & 1008 & \\
\hline Mnens & tanar & 3 & 15 & & \\
\hline Atai & & 192 & 2000 & & \\
\hline
\end{tabular}

Table 5-Correlations for Religiosity

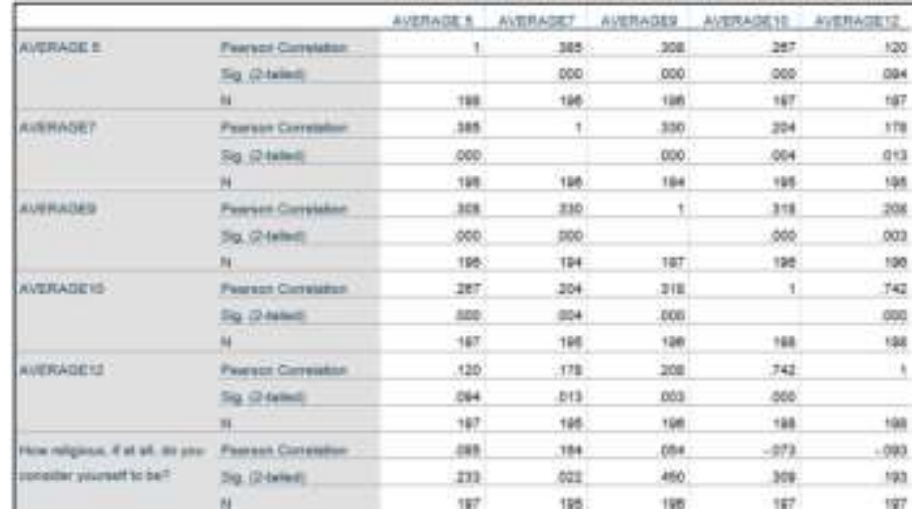

Table 6 - Correlations for Age

\begin{tabular}{|c|c|c|c|c|c|c|c|}
\hline & & $\begin{array}{l}\operatorname{mins}_{\text {es }} \\
\text { Es }\end{array}$ & $\begin{array}{l}\text { MIEST } \\
\text { I7 }\end{array}$ & $\begin{array}{c}\text { avenda } \\
\text { Eq }\end{array}$ & $\begin{array}{c}\text { antuat } \\
\text { an }\end{array}$ & $\begin{array}{l}\text { averair } \\
\text { Iz }\end{array}$ & $\begin{array}{l}\text { Whatis } \\
\text { mar ave }\end{array}$ \\
\hline \multirow[t]{3}{*}{ atrenset } & Cramel & $i$ & 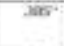 & 300 & 36 & 320 & $\omega 00$ \\
\hline & be if insen & & 000 & 000 & ane & sm & का \\
\hline & n & 100 & 120 & 106 & is & 100 & 105 \\
\hline \multirow[t]{3}{*}{ Avanat } & Consen: & sin & I & ज्ञा & 245 & 178 & 121 \\
\hline & sos n take? & .000 & & 100 & Ant & 613 & 003 \\
\hline & n & iss & 126 & 104 & ass & iss & is \\
\hline \multirow[t]{3}{*}{ avance } & Parnestiten & $x^{\circ}$ & 3ब & 1 & $3 \pm 5$ & zer & 106 \\
\hline & aen-tiano & 3000 & 000 & & ano & 301 & 100 \\
\hline & n & $19 \%$ & 194 & $19 \pi$ & 190 & $15 \%$ & 194 \\
\hline \multirow[t]{3}{*}{ ansanga } & Manes: & 207 & 200 & $31 \%$ & I & $.744^{2}$ & $10 \%$ \\
\hline & 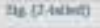 & 2000 & S04 & 500 & & 000 & Dia \\
\hline & $\kappa$ & 197 & 196 & $10 \%$ & ist & 100 & $1 \%$ \\
\hline \multirow[t]{3}{*}{ Averat } & Corveritai & 1.200 & De & $20 \pi$ & .242 & 1 & 102 \\
\hline & sepcuter & 694 & ois & 509 & $a n$ & & 15. \\
\hline & * & 198 & 108 & 190 & is & 396 & 150 \\
\hline \multirow[t]{3}{*}{ meres of } & 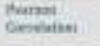 & $n$ & 121 & $\sin$ & $30 \%$ & 30 & $i$ \\
\hline & ses pringen & $m$ & 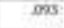 & 140 & na & 154 & \\
\hline & n & 195 & 193 & 194 & 193 & 198 & 100 \\
\hline
\end{tabular}


Table 7 - Correlations for Income

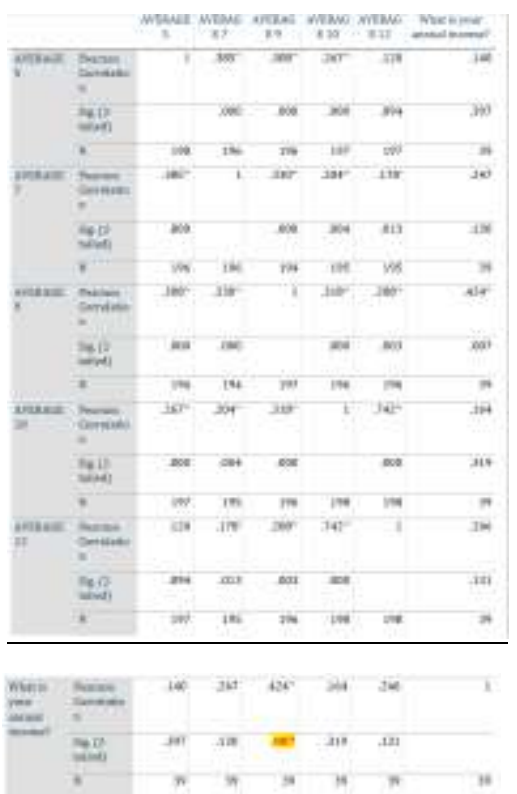

Table 8 - Correlations for Number of Children

\begin{tabular}{|c|c|c|c|c|c|c|c|}
\hline & & woreent & $\operatorname{argha}$ & $\operatorname{Nogan}_{n=0}$ & mavar & जв & 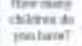 \\
\hline \multirow[t]{3}{*}{ 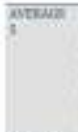 } & Nonise & 1 & क्ष: & In & JE & $7 \pi$ & कot \\
\hline & the & & $\mathrm{nec}$ & 000 & 200 & $\mathrm{mon}$ & 200 \\
\hline & 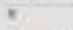 & $1 \times$ & 16 & 15: & $m$ & 167 & $16 \mathrm{~T}$ \\
\hline \multirow[t]{3}{*}{ Mrevin } & torrats & $M \bar{y}$ & 1 & $3 \pi$ & Ines & Jar & +158 \\
\hline & wipe & $m$ & & an & sti & DII & ine \\
\hline & $=$ & 140 & 140 & $I M$ & 146 & 106 & 126 \\
\hline \multirow[t]{3}{*}{ greuse } & moses & ser & iv & 1 & Sat- & net & $a$ \\
\hline & tepe & $3 w$ & in & & 300 & 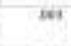 & $\pi$ \\
\hline & . & it & 14 & $\mathrm{mr}$ & in & 160 & tet \\
\hline \multirow[t]{3}{*}{ MIINA } & Lenests & $2 n$ & sor &  & t & $T N$ & in \\
\hline & Mig & 000 & Net & $=000$ & & ise & ats \\
\hline & $*$ & nd & 158 & tw & 7a & 19 & int \\
\hline \multirow[t]{3}{*}{ แัน } & Dents & 100 & $S N$ & $\sin$ & $34:$ & i & nie \\
\hline & wis & nt & on & 000 & 900 & & sin \\
\hline & $*$ & al & 10 & 10 & 10 & 78 & teit \\
\hline \multirow[t]{3}{*}{ comens } & nomber. & ans & 158 & set & iet & sia & i \\
\hline & ses & tais & +0 & nes & Eat & IA & \\
\hline & * & 362 & 100 & 143 & 162 & 162 & 161 \\
\hline
\end{tabular}

